\title{
Behaviour during Malolactic Fermentation of Three Strains of Oenococcus oeni Used as Direct Inoculation and Acclimatisation Cultures
}

\author{
P.M. Izquierdo Cañas ${ }^{1,2 *}$, E. García Romero ${ }^{1}$, F. Pérez Martín ${ }^{3}$, S. Seseña Prieto 3 , J.M. Heras Manso ${ }^{4}$, M.L. Palop Herreros ${ }^{3}$ \\ (1) Instituto de la Vid y el Vino de Castilla-La Mancha, Ctra. Toledo-Albacete s/n. 13700 Tomelloso (Ciudad Real), Spain \\ (2) Parque Científico y Tecnológico de Albacete, Paseo de la Innovación, 1, 02006 Albacete, Spain \\ (3) Departamento de Química Analítica y Tecnología de Alimentos, Facultad de Ciencias del Medio Ambiente, Universidad de \\ Castilla-La Mancha, Avda. Carlos III, 21, 45071 Toledo, Spain \\ (4) Lallemand Inc., Spain and Portugal
}

Submitted for publication: April 2012

Accepted for publication: October 2012

Key words: Direct inoculation cultures (MBR $®$ ), acclimatisation cultures (1-STEP $\left.{ }^{\circledR}\right)$, MLF, Oenococcus oeni

\begin{abstract}
The behaviour in malolactic fermentation (MLF) of an autochthonous strain of Oenococcus oeni, C22L9, isolated from a winery in Castilla-La Mancha (Spain), and of two other commercial strains of O. oeni, PN4 and Alpha (Lallemand Inc.), inoculated by direct inoculation (MBR®) and after a short acclimatisation phase (1-STEP®), was studied. Strain C22L9 carried out MLF slightly faster than the two other commercial strains, leading to a lower increase in volatile acidity and in 2,3-butanedione and 3-hydroxy-2-butanone concentrations, a higher lactic acid content, lower degradation of citric acid and increased degradation of ethanol. No great differences were observed in the duration of MLF, although the acclimatisation cultures were slightly faster, or in the composition of the wines when using the $O$. oeni strains in the form of MBR ${ }^{\circledR}$ or 1-STEP ${ }^{\circledR}$ cultures. The tasters did not detect significant differences in the wines obtained from the same strain of $O$. oen $i$ in the two inoculation formats.
\end{abstract}

\section{INTRODUCTION}

Malolactic fermentation (MLF) is generally considered to be a desirable transformation in the winemaking process. This process, in which L-malic acid is decarboxylated into L-lactic acid and $\mathrm{CO}_{2}$, is carried out by lactic acid bacteria (LAB) and results in the de-acidification and greater microbiological stability of the wine. In addition, many other secondary metabolic reactions occur, producing changes in the organoleptic properties of wines (Lonvaud-Funel, 1999; Ugliano et al., 2003), which are also dependent on the bacterial strain responsible for MLF (Costello, 2006).

Previous reports have shown the presence of different species and strains of LAB in spontaneous MLF, although Oenococcus oeni has been described as the predominant species (Wibowo et al., 1985; Lonvaud-Funel, 1999; Guerrini et al., 2003; Izquierdo Cañas et al., 2009).

MLF is usually performed by the autochthonous microbiota present in grapes and cellars, but sometimes the process takes weeks and it does not always achieve satisfactory results (Agouridis et al., 2005). In order to induce and better control MLF, the inoculation of commercial malolactic starter cultures is becoming a common oenological practice in wineries (Bauer \& Dicks, 2004). However, the use of starter cultures is not always successful, because wine is a very harsh environment for bacterial growth (Coucheney et al., 2005). The growth of the inoculated bacteria and the time required to complete MLF are influenced by various environmental factors, such as the physicochemical parameters, the presence of energy sources and the existence of other microbiota in the wine (RibéreauGayon et al., 2006). The use of MLF starter cultures of LAB strains selected from the indigenous wine microbiota of each region takes advantage of the natural adaptation of the strains to the wine characteristics, and may simultaneously preserve the characteristics of regional wines (Izquierdo et al., 2004).

Strict criteria are used for the selection of the bacteria to be used as starter cultures (Krieger-Weber, 2009). These criteria include tolerance of low $\mathrm{pH}$ and high ethanol and $\mathrm{SO}_{2}$ concentrations, good growth characteristics under the winemaking conditions, compatibility with the Saccharomyces cerevisiae yeast used in alcoholic fermentation, ability to survive the production process, inability to produce biogenic amines, lack of off-flavour or offodour production, and the production of aroma compounds

*Corresponding author: E-mail: susana.sprieto@uclm.es

Aknowledgements: The authors wish to thank the Ministry of Education and Science of the Regional Autonomous Government of Castilla-La Mancha (JCCM) for project PCC 05-003-, and the winery Cooperativa Virgen de las Viñas de Tomelloso (Ciudad Real) for its contribution. P.M. Izquierdo Cañas acknowledges the European Social Fund and INCRECYT for co-funding his contract 
that may potentially contribute to a favourable wine aroma profile (Volschenk et al., 2006; Lerm et al., 2010). In the market, different companies commercialise various types of LAB starter cultures, which differ in their characteristics and the time required prior to being added to the wine (Lerm et al., 2010). The liquid suspension cultures have a shelf life of only two to 20 days and require a preparation time of three to seven days. The traditional freeze-dried cultures have to be rehydrated in a wine/water mixture and, consequently, a period of three to four days is required prior to addition to the wine. The quick build-up starter cultures (acclimatisation cultures) also require an additional rehydration/activation step, but they may be added to the wine in a shorter period of time (18 to 24 hours). In contrast, direct inoculation cultures do not need any special preparation and are added directly to the wine, although they are more expensive.

This study compares the results obtained from fermentation assays of Tempranillo red wine inoculated with the autochthonous $O$. oeni strain, C22L9, selected by Ruiz et al. (2010) from a collection of LAB isolates from Spanish red wines of the Castilla-La Mancha region, and with each of the $O$. oeni commercial strains PN4 and Alpha. The behaviour of freeze-dried direct inoculation cultures and acclimatisation cultures was also compared for each strain.

\section{MATERIALS AND METHODS}

\section{Fermentation assays}

Must of the Tempranillo grape variety, also called Cencibel, from Castilla-La Mancha vineyards, was fermented in an experimental cellar at the Vine and Wine Institute of Castilla-La Mancha (IVICAM) during the 2009 vintage. The chemical composition of the must was as follows: ${ }^{\circ}$ Bé 13.21 ; total acidity $5.35 \mathrm{~g} / \mathrm{L}$ tartaric acid; $\mathrm{pH} 3.42$; L-malic acid $2.91 \mathrm{~g} / \mathrm{L}$; citric acid $0.33 \mathrm{~g} / \mathrm{L}$. A controlled alcoholic fermentation at $25 \pm 2^{\circ} \mathrm{C}$ was carried out using the commercial yeast UvafermVN ${ }^{\circledR}$ (Lallemand Inc., Montreal, Canada). After the alcoholic fermentation, the wine was racked and distributed in eighteen 20-L tanks. For MLF, three strains of $O$. oeni were assayed: one autochthonous strain (C22L9) selected at our laboratory (Ruiz et al., 2010) and two commercial strains, PN4 and Alpha (Lallemand Inc.). Each strain was used as a direct inoculation culture $(\mathrm{MBR} \AA)$ and as an acclimatisation culture (1-STEP $\AA)$. The cultures were purchased from Lallemand Inc.

All the fermentations were performed in triplicate. The commercial preparations for direct inoculation (MBR $\AA$ ) and acclimatisation culture (1-STEP $\AA)$ were used according to the manufacturer's instructions, and the malolactic fermentation temperature was $22^{\circ} \mathrm{C}$.

MLF development was monitored by determining the L-malic acid and L-lactic acid content of the wines. When the malic acid content reached values $\leq 0.2 \mathrm{~g} / \mathrm{L}$, the wines were decanted and sulphited to reach a free $\mathrm{SO}_{2}$ concentration of $25.0 \mathrm{mg} / \mathrm{L}$ and, subsequently, clarified, stabilised and filtered through $0.2 \mu \mathrm{m}$ filters, following standard procedures, prior to bottling.

\section{Chemical analysis of the wines}

The wines were analysed before and after MLF. The most common chemical parameters of wine, namely alcohol degree, total acidity, $\mathrm{pH}$, volatile acidity, L-malic acid, L-lactic acid and citric acid contents, were analysed following official OIV methods (OIV, 2009).

\section{Analysis of volatile compounds}

The samples were analysed by GC/MS in SCAN mode using a Trace GC gas chromatograph (Thermo Quest) and a DSQII quadrupole mass analyser with an electronic impact source at $70 \mathrm{eV}$.

For the major volatile compounds, $200 \mathrm{~mL}$ of wine were steam-distilled to a volume of $200 \mathrm{~mL}$ (OIV, 2009). Then, $1 \mu \mathrm{L}$ of distilled wine with 4-methyl-2-pentanol as the internal standard was directly injected. The chromatographic conditions were as follows: CP-Wax $57 \mathrm{CB}$ (Varian Inc.), $50 \mathrm{~m} \times 0.32 \mathrm{~mm}$ and $0.2 \mu \mathrm{m}$ thick phase column, with helium as the carrier gas $(1.7 \mathrm{~mL} / \mathrm{min}$, split $1 / 25)$; injector temperature, $220^{\circ} \mathrm{C}$; transfer line temperature, $240^{\circ} \mathrm{C}$, and oven temperature, $43^{\circ} \mathrm{C}(5 \mathrm{~min}) ; 4^{\circ} \mathrm{C} / \mathrm{min} ; 100^{\circ} \mathrm{C}-20^{\circ} \mathrm{C} / \mathrm{min}$; $190^{\circ} \mathrm{C}(1 \mathrm{~min})$.

For the analysis of the minor volatile compounds, 500 $\mathrm{mL}$ of wine containing $100 \mu \mathrm{L}$ of $10 \mathrm{~g} / \mathrm{L} 4$-nonanol as the internal standard were extracted for $24 \mathrm{~h}$ with $250 \mathrm{~mL}$ of a 60:40 mixture of pentane-dichloromethane. The extracts were concentrated to $2 \mathrm{~mL}$ by distillation in a Vigreux column and kept at $-20^{\circ} \mathrm{C}$ until the time of analysis. Two $\mu \mathrm{L}$ of the extract were injected in a BP21 column (SGE), 50 $\mathrm{m} \times 0.32 \mathrm{~mm}$ internal diameter and $0.25 \mathrm{~mm}$ thickness, in the FFAP phase (polyethylene glycol treated with TPA). The chromatographic conditions were: oven temperature, $43^{\circ} \mathrm{C}$ (15 min); $2^{\circ} \mathrm{C} / \mathrm{min} ; 125^{\circ} \mathrm{C}-1^{\circ} \mathrm{C} / \mathrm{min} ; 150^{\circ} \mathrm{C}-4^{\circ} \mathrm{C} / \mathrm{min} ; 200^{\circ} \mathrm{C}$ (45 $\mathrm{min})$, and helium as the carrier gas $(1.4 \mathrm{~mL} / \mathrm{min}$, split $1 / 15$, splitless time $0.5 \mathrm{~min}$ ).

The compounds that were separated were identified by their mass spectra and their chromatographic retention times, using commercial products as a standard. The quantification was performed by analysing the characteristic $\mathrm{m} / \mathrm{z}$ fragment for each compound using the internal standard method. The results for the non-available products are shown as the ratio between the area of each compound and that of the internal standard.

\section{Sensory analysis}

Sensory analysis was performed in order to determine whether differences were perceived between the wines obtained from the different strains and from the MBR $\AA$ and 1-STEP $®$ forms. A triangular test (ISO Standard 4120, 1983) was carried out by 14 assessors. A significance level of 5\% was chosen.

\section{Statistical analysis}

The Student-Newman-Keuls test for multiple comparisons of the means was carried out in order to determine whether there were significant differences between the results obtained from the chemical and the volatile compound analyses. Multivariate data analysis (PCA) was used to obtain an overview of the chemical and volatile compounds analysed and to investigate possible correlations between the samples. SPSS 12.0 software (IBM, USA) was used for both analyses. 


\section{RESULTS AND DISCUSSION}

Evolution of malolactic fermentation

Figure 1 shows the evolution of the malic acid content of the wines following inoculation with the assayed strains used as MBR $\AA$ and 1-STEP $\AA$ cultures. Between 11 and 16 days were necessary to reach a malic acid content lower than $0.2 \mathrm{~g} / \mathrm{L}$. In all cases, the degradation of malic acid was very slow during the first days following the inoculation. This fact has already been reported by other authors (Ugliano \& Moio, 2005) and has been attributed to the characteristic of wine, such as the $\mathrm{pH}$ and the alcohol and $\mathrm{SO}_{2}$ contents, which make wine a very harsh environment for bacterial growth (Coucheney et al., 2005).

The two commercial strains, PN4 and Alpha, required a somewhat longer period (between one and three days) to consume the malic acid compared to the C22L9 strain. For this strain, no differences were observed in the duration of MLF when it was used as an MBR $\AA$ or a 1-STEP $\AA$ culture; however, the duration of MLF was slightly longer when PN4 and Alpha were used in the MBR ${ }^{\circledR}$ form.

\section{Chemical and volatile composition}

The results for the chemical parameters and the volatile compounds most closely related to MLF are shown in Table 1. A decrease in the total acidity of between 0.79 to
$1.08 \mathrm{~g} / \mathrm{L}$ was observed in all the wines following MLF, and no significant differences were observed between the strains of $O$. oeni used. As a consequence, an increase in the $\mathrm{pH}$ was obtained, ranging between 0.12 and 0.16 units for the two commercial strains, and between 0.45 and 0.48 units for the C22L9 strain. The greater increase in the $\mathrm{pH}$ of wines from the C22L9 strain could be attributable partially to a higher production of lactic acid and a lower production of volatile acidity, as shown in Table 1, although other factors, such as the formation of organic acid salts, as reported by Aladrén (2004), may also have had an influence.

The increase in the volatile acidity of the wines (between 0.01 and $0.12 \mathrm{~g} / \mathrm{L}$ ) was similar to that reported by other authors (Bartowsky \& Henschke, 1995). The lowest increase in the volatile acidity was observed in the wines in which MLF had been carried out with the C22L9 strain used as a 1-STEP ${ }^{\circledR}$ culture. Moreover, the autochthonous strain C22L9 yielded a slightly higher lactic acid content and a lower degradation of citric acid than the two other strains. In contrast, the commercial strain PN4 exhibited the highest degradation of citric acid and, as a consequence, these wines had significantly higher concentrations of 2,3-butanodione and 3-hidroxy-2-butanone, secondary metabolites from citric acid degradation (Table 1 ).

Furthermore, it was observed that the two commercial

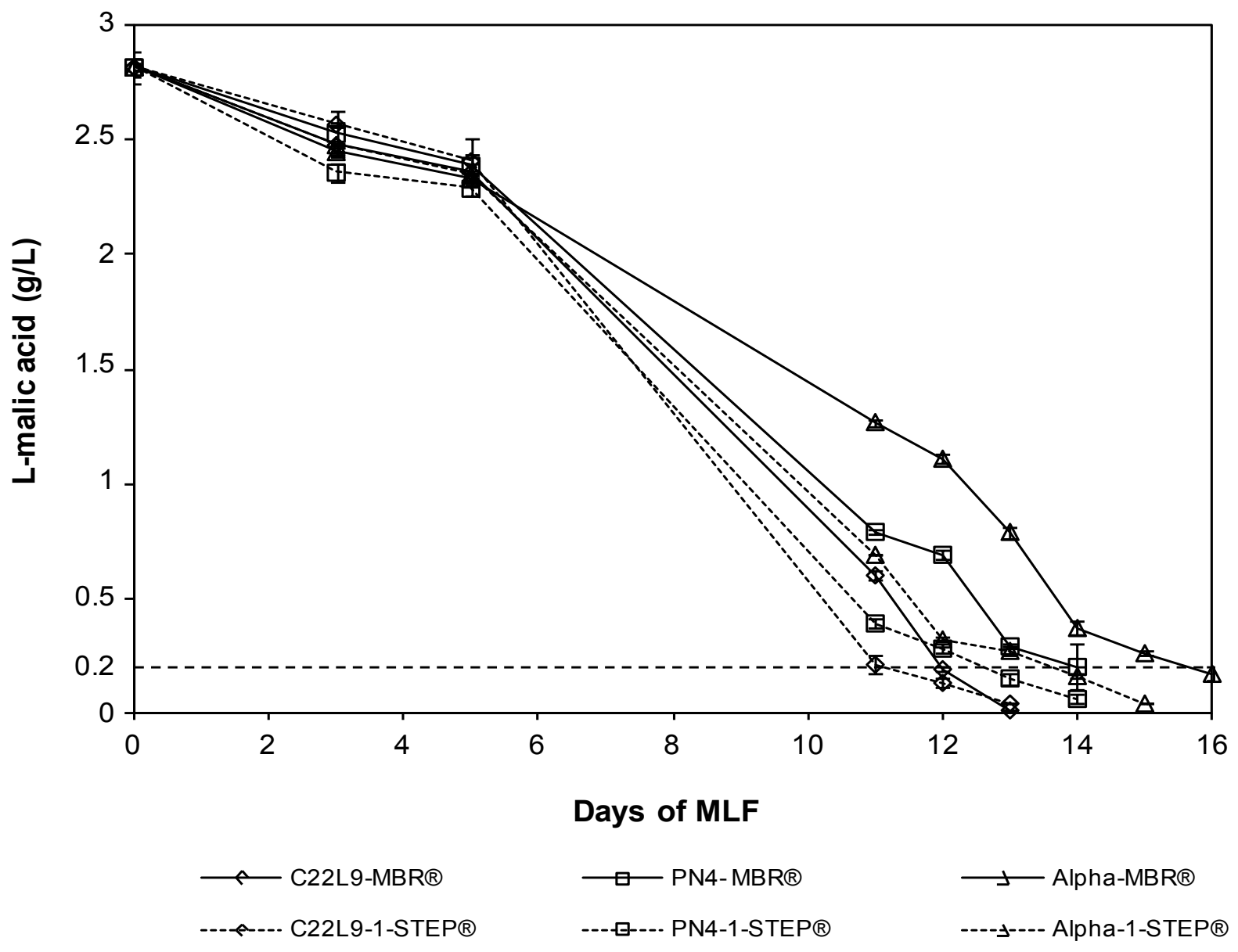

FIGURE 1

Evolution of L-malic acid in wines after inoculation with strains of $O$. oeni, C22L9, PN4 and Alpha, used as MBR $®$ and 1 -STEP $®$ cultures. 
TABLE 1

Chemical parameters and the most important volatile compounds in wines inoculated with the selected autochthonous strain of O. oeni, C22L9, and two commercial strains of $O$. oeni, PN4 and Alpha, used as MBR ${ }$ and 1-STEP ${ }^{\circ}$ cultures.

\begin{tabular}{|c|c|c|c|c|c|c|c|c|c|c|c|c|c|}
\hline & \multirow{3}{*}{$\begin{array}{l}\text { Before } \\
\text { MLF }\end{array}$} & \multicolumn{4}{|c|}{ C22L9 } & \multicolumn{4}{|c|}{ PN4 } & \multicolumn{4}{|c|}{ Alpha } \\
\hline & & \multicolumn{2}{|c|}{ MBR ${ }^{\circledR}$} & \multicolumn{2}{|c|}{ 1-STEP ${ }^{\circledR}$} & \multicolumn{2}{|c|}{ MBR ${ }^{\circledR}$} & \multicolumn{2}{|c|}{ 1-STEP ${ }^{\circledR}$} & \multicolumn{2}{|c|}{$\operatorname{MBR}{ }^{\circledR}$} & \multicolumn{2}{|c|}{ 1-STEP ${ }^{\circledR}$} \\
\hline & & Mean & SD & Mean & SD & Mean & SD & Mean & SD & Mean & SD & Mean & SD \\
\hline Alcohol (\% vol/vol) & 13.84 & 13.73 & 0.06 & 13.69 & 0.04 & 13.70 & 0.16 & 13.60 & 0.05 & 13.66 & 0.02 & 13.63 & 0.02 \\
\hline Total acidity $(\mathrm{g} / \mathrm{L})$ & 5.22 & 4.28 & 0.00 & 4.16 & 0.11 & 4.14 & 0.24 & 4.11 & 0.01 & 4.43 & 0.28 & 4.32 & 0.20 \\
\hline $\mathrm{pH}$ & 3.57 & $4.05^{\mathrm{d}}$ & 0.03 & $4.02^{\mathrm{c}}$ & 0.00 & $3.73^{b}$ & 0.03 & $3.71 \mathrm{ab}$ & 0.00 & $3.69^{\text {a }}$ & 0.00 & $3.72^{b}$ & 0.00 \\
\hline Volatile acidity $(\mathrm{g} / \mathrm{L})$ & 0.23 & $0.28^{b}$ & 0.02 & $0.24^{\mathrm{a}}$ & 0.02 & $0.30^{\mathrm{bc}}$ & 0.01 & $0.35^{\mathrm{d}}$ & 0.01 & $0.29^{b}$ & 0.01 & $0.31^{\mathrm{c}}$ & 0.01 \\
\hline L-malic acid (g/L) & 2.82 & $0.01^{\mathrm{a}}$ & 0.00 & $0.04^{\mathrm{a}}$ & 0.03 & $0.20^{\mathrm{b}}$ & 0.06 & $0.06^{\mathrm{a}}$ & 0.02 & $0.17^{\mathrm{b}}$ & 0.08 & $0.04^{\mathrm{a}}$ & 0.04 \\
\hline L-lactic acid (g/L) & 0.08 & $1.89^{\mathrm{b}}$ & 0.03 & $1.87^{\mathrm{b}}$ & 0.01 & $1.71^{\mathrm{a}}$ & 0.01 & $1.77 \mathrm{ab}$ & 0.16 & $1.78^{a b}$ & 0.08 & $1.85^{\mathrm{b}}$ & 0.00 \\
\hline Citric acid (g/L) & 0.32 & $0.28^{\mathrm{e}}$ & 0.01 & $0.28^{\mathrm{e}}$ & 0.00 & $0.15^{\mathrm{b}}$ & 0.01 & $0.09^{\mathrm{a}}$ & 0.01 & $0.24^{\mathrm{d}}$ & 0.04 & $0.20^{\mathrm{c}}$ & 0.01 \\
\hline 2.3-Butanedione (mg/L) & 1.83 & $3.54^{b}$ & 0.74 & $2.65^{\mathrm{a}}$ & 0.23 & $9.23^{\mathrm{d}}$ & 0.48 & $8.94^{\mathrm{d}}$ & 0.81 & $7.02^{c}$ & 0.46 & $9.06^{\mathrm{d}}$ & 0.37 \\
\hline 3-Hidroxy-2-butanone (mg/L) & 1.01 & $1.27^{\mathrm{a}}$ & 0.09 & $1.13^{\mathrm{a}}$ & 0.05 & $2.73^{\mathrm{d}}$ & 0.02 & $2.35^{\mathrm{c}}$ & 0.20 & $1.91^{\mathrm{b}}$ & 0.07 & $2.28^{\mathrm{c}}$ & 0.38 \\
\hline 2.3-Butanediol (mg/L) & 12.73 & $17.70^{a b}$ & 6.43 & $28.10^{\mathrm{d}}$ & 4.79 & $14.81^{\mathrm{a}}$ & 0.22 & $13.51^{\mathrm{a}}$ & 4.18 & $26.00^{\mathrm{cd}}$ & 4.46 & $21.22^{b c}$ & 0.91 \\
\hline Ethanal (mg/L) & 13.69 & $4.17^{\mathrm{a}}$ & 0.08 & $4.56^{\mathrm{ab}}$ & 0.31 & $4.84^{b}$ & 0.29 & $4.72^{\mathrm{ab}}$ & 0.09 & $5.47^{\mathrm{c}}$ & 0.82 & $6.59^{d}$ & 0.05 \\
\hline Ethyl lactate (mg/L) & 4.65 & $22.68^{\mathrm{a}}$ & 1.15 & $22.28^{\mathrm{a}}$ & 0.13 & $22.45^{\mathrm{a}}$ & 0.61 & $25.66^{\mathrm{b}}$ & 0.06 & $23.02^{\mathrm{a}}$ & 1.43 & $22.78^{\mathrm{a}}$ & 1.01 \\
\hline Diethyl succinate $(\mathrm{mg} / \mathrm{L})$ & 1.88 & 1.91 & 0.05 & 1.81 & 0.13 & 1.76 & 0.08 & 1.76 & 0.07 & 2.04 & 0.33 & 1.92 & 0.09 \\
\hline
\end{tabular}

Different superscripts ${ }^{(\mathrm{a}, \mathrm{b}, \mathrm{c})}$ indicate significant differences between the $O$. oeni strains assayed for $\alpha=0.05$ according to the Student-Newman-Keuls test. Values are the mean of triplicates. The initial wine data were not statistically compared.

strains in the form of MBR ${ }^{\circledR}$ cultures produced less lactic acid and degraded a lower quantity of citric acid than the corresponding 1-STEP ${ }^{\circledR}$ cultures, most likely due to the fact that they grew more slowly and degraded a lower quantity of malic acid. In contrast, the autochthonous strain C22L9 in both forms of inoculation degraded practically the same quantity of malic acid, producing similar concentrations of lactic acid and citric acid. These results indicate that the differences are not attributable to the type of starter culture (MBR ${ }^{\circledR}$ or $\left.1-\mathrm{STEP} \AA\right)$, but to the degree of progress of MLF and to the strain of $O$. oeni used.

One of the most important aromatic compounds produced by LAB in MLF is 2,3-butanedione, which at low concentrations (about $1.4 \mathrm{mg} / \mathrm{L}$ ) contributes positively to the wine aroma, supplying buttery notes and adding complexity to the wine (Martineau \& Henick-Kling, 1995; Bartowsky \& Henschke, 2004; Swiegers et al., 2005), while at high concentrations it depreciates the quality. It is formed as an intermediate product in the metabolism of citric acid (Bartowsky et al., 2002) and may be reduced to 3 -hydroxy-2-butanone; the latter, in turn, may be reduced to 2,3-butanediol (Costello, 2006).

The metabolism of citric acid begins at the end of MLF, when most of the malic acid has been transformed into lactic acid and, for this reason, the maximum concentration of 2,3-butanedione is reached when the malic acid is exhausted (Bartowsky \& Henschke, 2004).

It was observed that the degradation of citric acid and, consequently, the production of 2,3-butanedione and 3-hydroxy-2-butanone, were dependent on the strain of $O$. oeni used, with the C22L9 strain producing the lowest concentration of these compounds with both types of inoculation cultures $(\mathrm{MBR} \AA$ and 1-STEP $\AA)$. However, the degradation of malic acid with the C22L9 strain was greater than or equal to that of the two other commercial strains. No differences in the production of 2,3-butanedione were observed between the MBR ${ }^{\circledR}$ and 1-STEP $\AA$ cultures with any of the strains. 
Ethanal is another important compound associated with herbaceous and oxidative notes in wines (Osborne et al., 2000). In all cases, a decrease in the content thereof was observed with respect to the initial wine, and significant differences between the wines were noted depending on the strain of $O$. oen $i$ used. These results are similar to those reported by Pozo-Bayón et al. (2005), who also observed differences in the final concentration of ethanal in wines in which MLF had been carried out with different strains of O. oeni. For the C22L9 and Alpha strains, a lower decrease in the ethanal content was observed when they were used as 1-STEP® cultures.

The esters most closely related to MLF are ethyl lactate and diethyl succinate (Herjavec et al., 2001; Ugliano \& Moio, 2005; Izquierdo et al., 2008). Ethyl lactate is one of the most important by-products of the metabolism of lactic acid bacteria and is beneficial for the aroma of wines, supplying fruity and dairy notes and contributing to the sensations of roundness in the mouth (Ugliano \& Moio, 2005).
The concentration of ethyl lactate undergoes a significant increase following MLF, and some authors (Pozo-Bayón et al., 2005) have reported that the concentrations reached are dependent on the strain of $O$. oeni used. In our study, no significant differences in the production of ethyl lactate were observed between the different strains and the different modes of use.

Diethyl succinate also contributes to the aroma of wines, supplying fruity and melon notes. Its odour threshold is $1.2 \mathrm{mg} / \mathrm{L}$ (Peinado et al., 2004). Although the differences were not statistically significant, a higher content of this compound was observed in strains C22L9 and Alpha when used as MBR ${ }^{\circledR}$ cultures.

Table 2 shows the volatile compounds analysed in the wines grouped into families and Table 3 shows the results obtained for these groups of compounds. Linear alcohols contribute to the aromatic complexity of wine, supplying a fruity flavour when they are found at concentrations lower than $300 \mathrm{mg} / \mathrm{L}$. At concentrations above $400 \mathrm{mg} / \mathrm{L}$ they are

TABLE 2

Groups of volatile compounds analysed in the wines.

\begin{tabular}{|c|c|c|}
\hline Linear alcohols & Ethyl esters & Norisoprenoids \\
\hline Methanol & Ethyl butyrate & Damascenone \\
\hline Propanol & Ethyl hexanoate & $\beta$-Ionone \\
\hline Isobutanol & Ethyl octanoate & 3-Hydroxy- $\beta$-damascone \\
\hline 1-Butanol & Ethyl decanoate & $3-O x o-\alpha$-ionol \\
\hline 1-Pentanol & Ethyl dodecanoate & \\
\hline 3-Methyl-3-buten-1-ol & Ethyl hexadecanoate & Lactones \\
\hline \multirow[t]{2}{*}{ c-2-Penten-1-ol } & & $\gamma$-Butyrolactone \\
\hline & Ethyl phenols & $\gamma$-Caprolactone \\
\hline C6 alcohols & Phenol & 4-Ethoxy- $\gamma$-butyrolactone \\
\hline 1-Hexanol & 4-Ethyl-phenol & $4(1$-hydroxy-ethyl)- $\gamma$-butyrolactone \\
\hline t-3-Hexen-1-ol & 4-Ethyl-guaiacol & Pantolactone \\
\hline c-3-Hexen-1-ol & & Furaneol \\
\hline t-2-Hexen-1-ol & Methoxyphenols & \\
\hline \multirow[t]{2}{*}{ c-2-Hexen-1-ol } & Syringol & \\
\hline & Eugenol & \\
\hline Bencenic alcohols & Vanillin & \\
\hline Benzyl alcohol & Methyl vanillate & \\
\hline \multirow[t]{2}{*}{ 2-Phenylethanol } & Acetovanillone & \\
\hline & Propiovanillone & \\
\hline Acids & Zingerone & \\
\hline Hexanoic acid & Acetosyringone & \\
\hline Octanoic acid & Tyrosol & \\
\hline \multicolumn{3}{|l|}{ Decanoic acid } \\
\hline \multirow[t]{2}{*}{ Phenylacetic acid } & Terpenes & \\
\hline & $\alpha$-Terpineol & \\
\hline Acetates & Geraniol & \\
\hline Isobutyl acetate & Linalool & \\
\hline Isoamyl acetate & Hydroxylinalool & \\
\hline Hexyl acetate & Hydroxycitronelol & \\
\hline \multicolumn{3}{|l|}{ c-3-Hexenil acetate } \\
\hline 2-Phenylethyl acetate & & \\
\hline
\end{tabular}


TABLE 3

Mean value and standard deviation of the concentration of the volatile compounds analysed in the wines.

\begin{tabular}{|c|c|c|c|c|c|c|c|c|c|c|c|c|c|}
\hline & \multirow{3}{*}{$\begin{array}{l}\text { Before } \\
\text { MLF }\end{array}$} & \multicolumn{4}{|c|}{ C22L9 } & \multicolumn{4}{|c|}{ PN4 } & \multicolumn{4}{|c|}{ Alpha } \\
\hline & & \multicolumn{2}{|c|}{$\operatorname{MBR} \AA$} & \multicolumn{2}{|c|}{ 1-STEP ${ }^{\circledR}$} & \multicolumn{2}{|c|}{$\operatorname{MBR}{ }^{\circledR}$} & \multicolumn{2}{|c|}{ 1-STEP ${ }^{\circledR}$} & \multicolumn{2}{|c|}{$\operatorname{MBR}{ }^{\circledR}$} & \multicolumn{2}{|c|}{ 1-STEP $®$} \\
\hline & & Mean & SD & Mean & SD & Mean & SD & Mean & SD & Mean & SD & Mean & SD \\
\hline Linear alcohols (mg/L) & 124.75 & $162.69^{b}$ & 5.24 & $165.97^{b}$ & 8.14 & $141.79^{\text {a }}$ & 1.82 & $142.37^{\mathrm{a}}$ & 7.97 & $157.68^{b}$ & 16.30 & $161.07^{b}$ & 5.59 \\
\hline C6 alcohols (mg/L) & 2.65 & 3.08 & 0.13 & 2.89 & 0.24 & 3.05 & 0.06 & 2.83 & 0.13 & 2.97 & 0.02 & 2.84 & 0.23 \\
\hline Bencenic alcohols $(\mathrm{mg} / \mathrm{L})$ & 27.20 & $25.11 \mathrm{ab}$ & 1.17 & $24.71 \mathrm{ab}$ & 2.15 & $24.52 \mathrm{ab}$ & 1.41 & $22.55^{\mathrm{a}}$ & 1.56 & $27.85^{b}$ & 4.07 & 25.37 ab & 0.83 \\
\hline Acids (mg/L) & 5.18 & 5.98 & 0.68 & 6.01 & 0.57 & 5.20 & 0.68 & 5.97 & 0.15 & 6.15 & 0.64 & 6.01 & 0.09 \\
\hline Acetates $(\mathrm{mg} / \mathrm{L})$ & 1.82 & 1.65 & 0.54 & 1.65 & 0.55 & 1.72 & 0.18 & 1.61 & 0.42 & 1.97 & 0.03 & 1.98 & 0.01 \\
\hline Ethyl esters (mg/L) & 1.41 & 1.34 & 0.06 & 1.27 & 0.08 & 1.34 & 0.05 & 1.29 & 0.01 & 1.36 & 0.06 & 1.31 & 0.05 \\
\hline Ethyl phenols $(\mu \mathrm{g} / \mathrm{L})$ & 1.25 & 1.27 & 0.07 & 1.32 & 0.10 & 1.23 & 0.06 & 1.21 & 0.02 & 1.29 & 0.01 & 1.23 & 0.06 \\
\hline Methoxyphenols $(\mu \mathrm{g} / \mathrm{L})$ & 355 & $428^{a}$ & 107 & $581^{\mathrm{b}}$ & 87 & $370^{\mathrm{a}}$ & 66 & $367^{\mathrm{a}}$ & 62 & $560^{\mathrm{b}}$ & 35 & $470^{\mathrm{a}}$ & 27 \\
\hline Terpenes $(\mu \mathrm{g} / \mathrm{L})$ & 18 & $20^{\mathrm{ab}}$ & 1 & $20^{\mathrm{ab}}$ & 1 & $18^{\mathrm{a}}$ & 2 & $20^{\mathrm{ab}}$ & 0 & $21^{b}$ & 2 & $21^{\mathrm{ab}}$ & 0 \\
\hline Norisoprenoids $(\mu \mathrm{g} / \mathrm{L})$ & 10 & $10^{\mathrm{ab}}$ & 1 & $10^{a b}$ & 1 & $9^{\text {a }}$ & 0 & $10^{\mathrm{ab}}$ & 0 & 11 ab & 2 & $11^{\mathrm{b}}$ & 0 \\
\hline Lactones (mg/L) & 2.92 & 3.41 & 0.83 & 3.66 & 0.58 & 3.09 & 0.06 & 2.94 & 0.03 & 3.28 & 0.38 & 2.91 & 0.37 \\
\hline
\end{tabular}

Different superscripts ${ }^{(a, b, c)}$ indicate significant differences between the $O$. oeni tested for $\alpha=0.05$ according to the StudentNewman-Keuls test. Values are the mean of triplicates. The initial wine data were not statistically compared.

detrimental to the aroma (Swiegers et al., 2005). During MLF, the linear alcohol content increased and significant differences were observed between the strains, but not between the modes of use. The increases were greater for the C22L9 and Alpha strains. These results are consistent with those obtained by Maicas et al. (1999), who noted that the production of alcohols is dependent on the strain used to carry out MLF. Pozo-Bayón et al. (2005) also observed increases in the alcohols after MLF, but statistically significant differences were not reported.

The concentration of C6 alcohols, which contribute significantly to the wine aroma (Ugliano \& Henschke, 2008), also increased during MLF, although no significant differences were observed between the strains of $O$. oeni. Smaller increases were noted when the strains were used as $\mathrm{MBR} \AA$ cultures, albeit without statistically significant differences.

In contrast, a decrease in the content of bencenic alcohols was observed in all the wines, except those inoculated with the Alpha strain as an MBR ${ }^{\circledR}$ culture. Lower contents of bencenic alcohols were observed in the three strains of $O$. oeni when used in the 1-STEP ${ }^{\circledR}$ format.

Regarding the acid content, no statistically significant differences were observed between the three strains assayed or the inoculation cultures used, although in all cases there was a slight increase following MLF. It is worth noting that the total acid concentration was less than $20 \mathrm{mg} / \mathrm{L}$ in all the wines, which does not compromise the quality or the aroma of these wines (Pozo-Bayón et al., 2005). The significant contribution of these compounds to the wine aroma has been reported by various authors (Gómez-Mínguez et al., 2007; Mansfield et al., 2011).

The two main groups of esters associated with the fruity character of wines are acetates and ethyl esters. The production or hydrolysis of esters in MLF depends primarily on the LAB strains participating in the process (Izquierdo et al., 2008; Boido et al., 2009; Lerm et al., 2010), and there is disagreement regarding the influence of MLF on the final ester content in wines. Thus, some authors state that, during MLF, there are significant increases in the concentrations of some of the esters originating in alcoholic fermentation (Swiegers et al., 2005; Jeromel et al., 2008), whereas other authors have observed a decrease in the ester content during MLF, with a consequent decrease in fruitiness (Du Plessis et al., 2002).

The acetate and ethyl ester contents varied slightly during MLF. Increases or decreases were observed depending not only on the strains used, but also on their mode of use, either MBR $\AA$ or $1-S T E P \AA$ cultures, although the differences were not significant. Therefore, the fruity character of the wines 
was preserved.

Volatile phenols are a large family of compounds that participate in wine aroma, supplying very varied aromas (Zamora, 2003; Gerbaux et al., 2009). Different studies have determined the capacity of certain LAB to produce volatile phenols (Couto et al., 2006; Nelson, 2008), including ethylphenols. These compounds present an unpleasant animal odour, described as leather and even as horse sweat, and their presence at high concentrations, whenever it exceeds the perception threshold, is considered to be a serious defect in the wine (Ribéreau-Gayon et al., 1999). In our study, no significant differences in the content of ethylphenols were observed in the wines before or after MLF with any of the strains studied.

Regarding methoxyphenols, an increase was observed during MLF, and it was higher in the case of the C22L9 and Alpha strains. This led to an improvement in the aromatic characteristics of the wines, since this group of compounds imparts highly appreciated spicy aromas.

Terpenes, norisoprenoids and lactones are volatile compounds that are closely related to wine aroma (Izquierdo et al., 2008). As can be observed in Table 3, small differences between the strains were observed in the content of these families of compounds, although for some of them (i.e. terpenes) these differences were statistically significant.

\section{Multivariate data analysis}

Principal component analysis (PCA) was applied to the results obtained from the chemical and volatile compound analyses of the wines. Table 4 shows the variables with the highest correlation with principal component 1 (PC1) and principal component 2 (PC2). A total of $45.30 \%$ of the variance was explained by the first two principal components. Figure 2 shows the distribution of the wines on the plane formed by the two principal components PC1 and PC2. For PC1, two different groups were evident: the wines from strain PN4, to the right of $\mathrm{PC} 1$, and those from the autochthonous strain
C22L9 and the Alpha strain, located on the positive side of this axis. The latter had a higher content of propiovanillone, methyl vanillate and benzyl alcohol. Principal component 2 separated the wines of the PN4 and Alpha strains from those of $O$. oeni C22L9, which are located on the negative side of this axis. Wines from $O$. oeni C22L9 had a lower content of 2,3-butanedione, 3-hydroxy-2-butanone and ethanal, and a higher $\mathrm{pH}$ and citric acid content. It can also be observed that the wines obtained with strains PN4 and Alpha used in the 1-STEP ${ }^{\circledR}$ form were located at slightly higher values of PC2.

\section{Sensory analysis}

The results from the triangular test carried out in accordance with standard ISO 4120 for the pairs PN4-Alpha, C22L9Alpha and C22L9-PN4 showed significant differences only between wines from the C22L9 and PN4 strains, with a $95 \%$ confidence interval. The wines elaborated with the autochthonous strain of $O$. oeni C22L9 were preferred by $62.5 \%$ of the tasters when compared to the PN4 wines. When wines produced with the same strain in the two forms of inoculation (MBR $\AA$ and 1-STEP $\AA$ ) were compared, the tasters did not perceive significant differences.

\section{CONCLUSIONS}

From the results previously described it may be concluded that the autochthonous strain, C22L9, carries out a slightly more rapid MLF than the two other commercial strains assayed, leading to a higher lactic acid content, a higher degradation of ethanal and a lower degradation of citric acid and, as a consequence, a lower increase in the volatile acidity and a lower content of 2,3-butanedione and 3-hydroxy-2butanone at the end of MLF. In addition, wines from the C22L9 strain were preferred by $62.5 \%$ of the tasters when compared to the PN4 wines.

Regarding the volatile compounds, increases or decreases were observed depending on both the family of

TABLE 4

Results of principal component analysis (PCA) applied to the data from the chemical and volatile compound analyses.

\begin{tabular}{|c|c|c|c|}
\hline $\begin{array}{l}\text { Principal } \\
\text { component }\end{array}$ & $\begin{array}{c}\text { Variance } \\
\text { explained \% }\end{array}$ & $\begin{array}{c}\text { Total variance } \\
(\%)\end{array}$ & $\begin{array}{l}\text { Variables highly correlated with } \\
\text { the axis and their loadings }\end{array}$ \\
\hline \multirow{8}{*}{1} & \multirow{8}{*}{22.70} & \multirow{8}{*}{22.70} & Propiovanillone (0.903) \\
\hline & & & Methylvanillate (0.810) \\
\hline & & & Benzyl alcohol (0.781) \\
\hline & & & Damascenone (0.698) \\
\hline & & & Acetosyringone $(0.694)$ \\
\hline & & & Diethyl succinate (0.679) \\
\hline & & & 2-Phenylethanol (0.648) \\
\hline & & & L-lactic acid (0.619) \\
\hline \multirow{7}{*}{2} & \multirow{7}{*}{22.59} & \multirow{7}{*}{45.30} & 2,3-Butanodione $(0.851)$ \\
\hline & & & Zingerone (0.817) \\
\hline & & & $\mathrm{pH}(-0.803)$ \\
\hline & & & 3-Hidroxy-2-butanone (0.783) \\
\hline & & & Citric acid $(-0.701)$ \\
\hline & & & Ethanal $(0.692)$ \\
\hline & & & Volatile acidity $(0.687)$ \\
\hline
\end{tabular}




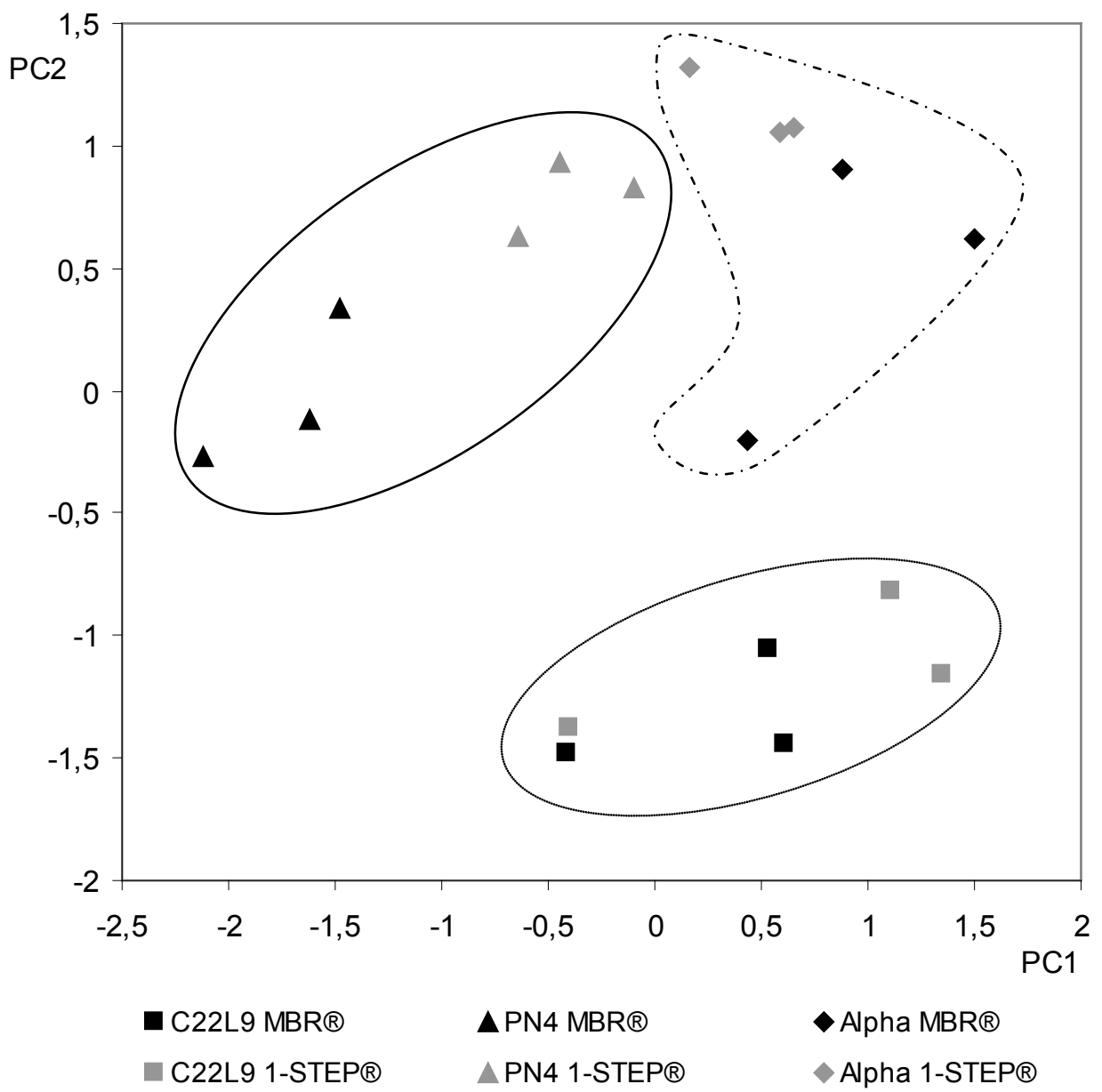

FIGURE 2

Distribution of the samples on the plane defined by the two principal components obtained by principal component analysis (PCA) of the data from the chemical and volatile compound analyses.

compounds and the strain of lactic acid bacteria used. Slight differences were observed for only a few of the compounds analysed (i.e. bencenic alcohols), depending on the type of culture used.

Big differences were not observed in the development of MLF or in the composition of the wines for the different inoculation formats used, and the tasters did not perceive significant differences when comparing wines from the same strain in the two formats.

In the light of these results, it may be stated that the use of the autochthonous strain of $O$. oeni with any of the formats assayed is highly recommended, because it is effective and applicable to different types of elaboration and cellars. Therefore, criteria such as the cost or the availability of the different forms of culture will be conclusive when choosing one of these types of cultures in winemaking.

\section{LITERATURE CITED}

Agouridis, N., Bekatorou, A., Nigam, P. \& Kanellaki, M., 2005. Malolactic fermentation in wine with Lactobacillus casei cells immobilized on delignified cellulosic material. J. Agric. Food Chem. 53, 2546-2551.

Aladrén, E.F., 2004. Estudio del nivel de potasio en el peciolo de la hoja y su relación con el $\mathrm{pH}$ y concentración de potasio en el vino. Vitic. Enol. Prof. 90, 7-16.
Bartowsky, E. \& Henschke, P.A., 1995. Malolactic fermentation and wine flavour. Aust. N.Z. Grapegrow. Winemak. 378, 83-94.

Bartowsky, E. \& Henschke, P.A., 2004. The "buttery" attribute of winediacetyl - desirability, spoilage and beyond. Int. J. Food Microbiol. 96, 325352 .

Bartowsky, E., Costello, P. \& Henschke, P.A., 2002. Management of malolactic fermentation-wine flavour manipulation. Aust. N. Z. Grapegrow. Winemak. 461, 7-8 and 10-12.

Bauer R. \& Dicks, L.M.T., 2004. Control of malolactic fermentation in wine. A review. S. Afr. J. Enol. Vitic. 25, 74-88.

Boido, E., Medina, K., Fariña, L., Carrau, F., Versini, G. \& Dellacasa, E., 2009. The effect of bacterial strain and aging on the secondary volatile metabolites produced during malolactic fermentation of Tannat red wine. J. Agric. Food Chem. 57, 6271-6278.

Costello, P., 2006. The chemistry of malolactic fermentation. In: Morenzoni, R. (eds.). Malolactic fermentation in wine - understanding the science and the practice. Lallemand, Montreal. pp. $1-11$.

Coucheney, F., Desroche, N., Bou, M., Tourdot-Maréchal, R., Dulau, L. \& Guzzo, J., 2005. A new approach for selection of Oenococcus oeni strains in order to produce malolactic starters. Int. J. Food Microbiol. 105, 463-470.

Couto, J.A., Campos, F.M., Figueiredo, A.R. \& Hogg, T.A., 2006. Ability of lactic acid bacteria to produce volatile phenols. Am. J. Enol. Vitic. 57, 166-171. 
Du Plessis, H.W., Steger, C.L., Du Toit, M. \& Lambrechts, M.G., 2002. The occurrence of malolactic fermentation in brandy base wine and its influence on brandy quality. J. Appl. Microbiol. 92 (5), 1005-1013.

Gerbaux, V., Briffox, C., Dumont, A. \& Sibylle, K., 2009. Influence of inoculation with malolactic bacteria on volatile phenols in wines. Am. J. Enol. Vitic. 60, 233-235.

Gómez-Mínguez, M.J., Cacho, J.F., Ferreira, V., Vicario, I.M. \& Heredia, F.J., 2007. Volatile

components of Zalema white wines. Food Chem. 100, 1464-1473.

Guerrini, S., Bastianini, A., Blaiotta, G., Granchi, L., Moschetti, G., Coppola, S., Romano, P. \& Vicenzini, M., 2003. Phenotypic and genotypic characterization of Oenococcus oeni strains isolated from typical Italian wines. Int. J. Food Microbiol. 83, 1-14.

Herjavec, S., Tupajic, P. \& Majdak, A., 2001. Influence of malolactic fermentation on the quality of Riesling wine. Agric. Conspec. Sci. 66, 5964.

ISO Standard 4120, 1983. Sensory analysis. Methodology Triangular Test. Austrian Standards Institute.

Izquierdo, P.M., García E., Martínez, J. \& Chacón, J.L., 2004. Selection of lactic bacteria to induce malolactic fermentation in red wine of $\mathrm{cv}$. Cencibel. Vitis 43, 149-153.

Izquierdo, P.M., García, E., Gómez, S. \& Palop, M.L., 2008. Changes in the aromatic composition of Tempranillo wines during spontaneous malolactic fermentation. J. Food Compos. Anal. 21, 724-730.

Izquierdo Cañas, P.M., Ruíz Pérez, P., Seseña Prieto, S. \& Palop Herreros, M.L., 2009. Ecological study of lactic acid microbiota isolated from Tempranillo wines of Castilla-La Mancha. J. Biosci. Bioeng. 108, 3, 220 224.

Jeromel, A., Herjavec, S., Orlic, S., Redzepovic, S. \& Wondra, M., 2008. Changes in volatile composition of Kraljevina wines by controlled malolactic fermentation. J. Cent. Eur. Agric. 9, 363-372.

Krieger-Weber, S., 2009. Application of yeast and bacteria as starter cultures. In: Konig, H., Unden, G. \& Frohlich. J. (eds). Biology of microorganisms on grapes, in must and in wine. Springer, Berlin. pp. 498-511.

Lerm, E., Engelbrecht, L. \& Du Toit, M., 2010. Malolactic fermentation: The ABC' of MLF. S. Afr. J. Enol. Vitic. 31, 2, 186-212.

Lonvaud-Funel, A., 1999. Lactic acid bacteria in the quality improvement and depreciation of wine. Anton. Leeuw. Int. J. 76, 317-331.

Maicas, S., Gil, J.V., Pardo, I. \& Ferrer, S., 1999. Improvement of volatile composition of wines by controlled addition of malolactic bacteria. Food Res. Int. 32, 491-496.

Mansfield, A.K., Schirle-Keller, J.P. \& Reineccius, G.A., 2011.

Identification of odor-impact compounds in red table wine produced from

Frontenac grapes. Am. J. Enol. Vitic. 62(2), 169-176.

Martineau, B. \& Henick-Kling, T., 1995. Performance and diacetyl production of commercial strains of malolactic bacteria in wine. J. Appl. Bacteriol. 78, 526-536.
Nelson, L., 2008. The production of volatile phenols by wine microorganisms. Thesis, Stellenbosch University, Private Bag X1, 7602 Matieland (Stellenbosch), South Africa.

O.I.V., 2009. Compendium of International Methods of Wine and Must Analysis. Ed. O.I.V., Paris.

Osborne, J.P., Mira de Orduña, R., Pilone, J.G. \& Liu, S.Q., 2000. Acetaldehyde metabolism by wine lactic acid bacteria. FEMS Microbiol. Lett. 91, 51-55.

Peinado, R.A., Moreno, J., Bueno, J.E., Moreno, J.A. \& Mauricio, J.C., 2004. Comparative study of aromatic compounds in two young white wines subjected to pre-fermentative cryomaceration. Food Chem. 84, 589-590.

Pozo-Bayon, M.A., G-Alegría, E., Polo, M.C., Tenorio, C., MartínÁlvarez, P.J., Calvo de la Banda, M.T., Ruiz-Larrea, F. \& Moreno-Arribas, M.V., 2005. Wine volatile and amino acid composition after malolactic fermentation: effect of Oenococcus oeni and Lactobacillus plantarum starter cultures. J. Agric. Food Chem. 53, 8729-8735.

Ribéreau-Gayon P., Dubourdieu D., Donèche B. \& Lonvaud-Funel A., 2006 $\left(2^{\text {nd }}\right.$ ed). Handbook of enology: The microbiology of wine and vinifications vol. 1. John Wiley \& Sons, Ltd. England.

Ribéreau-Gayon, P., Glories, Y., Maujean, A.Y. \& Dubourdieu, D., 1999. Chemical nature, origins and consequences of the main organoleptic defects. In: Handbook of enology, Vol 2. John Wiley \& Sons Ltd, Chichester. pp. 209-253.

Ruiz, P., Izquierdo, P.M., Seseña, S. \& Palop, M.L1., 2010. Selection of autochthonous Oenococcus oeni strains according to their oenological properties and vinification results. Int. J. Food Microbiol. 137, 230-235.

Swiegers, J.H., Bartowsky, E.J., Henschke, P.A. \& Pretorius, I.S., 2005. Yeast and bacterial modulation of wine aroma and flavour. Aust. J. Grape Wine Res. 11, 139-173.

Ugliano, M. \& Henschke, P.A., 2008. Yeast and wine flavour. In: MorenoArribas, M.V. \& Polo, C. (eds). Wine chemistry and biochemistry. Springer, New York. pp. 328-348.

Ugliano, M. \& Moio, L., 2005. Changes in the concentration of yeastderived volatile compounds of red wine during malolactic fermentation with four commercial starter cultures of Oenococcus oeni. J. Agric. Food Chem. 53, 10134-10139.

Ugliano, M., Genovese, A. \& Moio, L., 2003. Hydrolysis of wine aroma precursors during malolactic fermentation with four commercial starter cultures of Oenococcus oeni. J. Agric. Food Chem. 51, 5073-5078.

Volschenk, H., Van Vuuren, H.J.J. \& Viljoen-Bloom, M., 2006. Malic acid in wine: Origin, function and metabolism during vinification. S. Afr. J. Enol. Vitic. 27, 123-136.

Wibowo, D., Eschenbruch, R., Davis, C.R., Fleet, G.H. \& Lee, T.H., 1985. Occurrence and growth of lactic acid bacteria in wine: A review. Am. J. Enol. Vitic. 36, 302-313.

Zamora, F., 2003. Elaboración y crianza del vino tinto; aspectos científicos y prácticos. Editorial Mundi-Prensa; AMV Ediciones, Madrid. 